


\title{
Make-Up and Suspicion in Acquiring-a-Company. An experiment controlling for gender and gender constellations
}

\author{
Daniela Di Cagno \\ Luiss Guido Carli University of Rome, Rome, Italy \\ Arianna Galliera \\ Luiss Guido Carli University of Rome, Rome, Italy \\ Werner Güth \\ Max Planck Institute of Economics, Jena, Germany \\ Noemi Pace \\ University Ca' Foscari of Venice, Venice, Italy \\ Luca Panaccione \\ DEDI and CEIS, University of Rome Tor Vergata
}

\begin{abstract}
The privately informed seller of a company sends a value message to the uninformed potential buyer who then proposes a price for the company. "Make-up" is measured by how much the true value is overstated, "Suspicion" by how much the price offer differs from the value message. Treatments vary in information about gender via (not) informing about the gender constellation and in embeddedness of gender information. Female participants engage more in "make-up", i.e. overstate more the value of the company, but are not more "suspicious". Furthermore, homogeneous female constellations make up more.
\end{abstract}

Keywords: bargaining, experiment, gender

JEL Codes: C78, C91, J16

Address for correspondence: Noemi Pace

Department of Economics Ca' Foscari University of Venice Cannaregio 873, Fondamenta S.Giobbe 30121 Venezia - Italy Phone: (++39) 0412349187 Fax: (++39) 0412349176 e-mail: n.pace@unive.it

This Working Paper is published under the auspices of the Department of Economics of the Ca' Foscari University of Venice. Opinions expressed herein are those of the authors and not those of the Department. The Working Paper series is designed to divulge preliminary or incomplete work, circulated to favour discussion and comments. Citation of this paper should consider its provisional character.

The Working Paper Series is available only on lin (http://www.unive.it/nqcontent.cfm?a id=86302) For editorial correspondence, please contact: wp.dse@unive.it
Department of Economics

Ca' Foscari University of Venice

Cannaregio 873, Fondamenta San Giobbe

30121 Venice Italy

Fax: ++39041 2349210 


\title{
Make-Up and Suspicion in Acquiring-a-Company. An experiment controlling for gender and gender constellations
}

\author{
D. Di Cagno *, A. Galliera ${ }^{\dagger}$, W. Güth ${ }^{\ddagger}$, N. Pace ${ }^{\S}$, L. Panaccione ${ }^{\natural}$
}

November 11, 2014

*Luiss Guido Carli University of Rome, Rome, Italy, e-mail: ddicagno@luiss.it

${ }^{\dagger}$ Luiss Guido Carli University of Rome, Rome, Italy, email: agalliera@luiss.it

${ }^{\ddagger}$ Max Planck Institute of Economics, Jena, Germany, e-mail: gueth@econ.mpg.de

${ }^{\S}$ Department of Economics, University Ca' Foscari of Venice, Venice, Italy, e-mail: n.pace@unive.it

`DEDI and CEIS, University of Rome Tor Vergata, e-mail: luca.panaccione@uniroma2.it 


\begin{abstract}
The privately informed seller of a company sends a value message to the uninformed potential buyer who then proposes a price for the company. "Make-up" is measured by how much the true value is overstated, "Suspicion" by how much the price offer differs from the value message. Treatments vary in information about gender via (not) informing about the gender constellation and in embeddedness of gender information. Female participants engage more in "make-up", i.e. overstate more the value of the company, but are not more "suspicious". Furthermore, homogeneous female constellations make up more.
\end{abstract}

Keywords: bargaining, experiment, gender.

JEL: C78; C91; J16

\title{
1 Introduction
}

Unlike much of gender research in experimental economics, we do not focus on the usual differences in risk, delay, inequity, ... aversion, but on overstating the value of what one wants to sell and on suspicion as revealed by not believing such value claims. Our experimental workhorse is a modification of the "Acquiring-a-Company" game (Samuelson and Bazerman, 1985): after learning the value $v \in(0,1)$, the seller can send a value message $\hat{v}=\hat{v}(v)$ to the potential buyer who then proposes a price $p=p(\hat{v})$, which the buyer can accept $\delta=\delta(p, v)=1$, or not, $\delta=\delta(p, v)=0$. The payoff is $\delta(p-q v)$ for the seller and $\delta(v-p)$ for the buyer, where $q \in(0,1)$ is commonly known as well as that the buyer is risk-neutral and expecting $v$ to be uniformly distributed between 0 and 1. According to these assumptions the buyer will offer either $p=0$ for $q>\frac{1}{2}$ and $p=q$ for $q<\frac{1}{2}$. We are interested in how $\hat{v}-v, \hat{v}-p$ and $\delta(p, v)$ depend on gender, gender constellation, and whether one can condition only on gender or also on field of study (economics vs. non-economics). We expect women to make up more, larger $\hat{v}-v$, to be more "suspicious", larger $\hat{v}-p$, and to trade more with female than with male partners.

\section{The Experiment}

Our experimental setting is one of bargaining whether to trade and, if so, at which price. In this sense, our study is in line with those on gender differences in bargaining (Eckel and Grossman, 2001; Saad and Tripatl, 2001; Solnick, 2001; Riley and McGinn 2002; Gneezy and Rustichini, 2004; Niederle and 
Vesterlund, 2007; Sutter et al. 2009; García-Gallego 2012). However, we add new insights in gender research, by introducing "make-up" and "suspicion". We interpret "make-up", i.e. stating $\hat{v}=\hat{v}(v)>v$, as cheating, in line with a related study (Mechtenberg, 2009) that also allows for cheap-talk lying. We interpret "suspicion", i.e. stating $p=p(\hat{v})<\hat{v}$, as underpricing. Moreover, we control not only for gender but also for gender constellation. We run three treatments differing in information only: in U (unknown), trading partners randomly matched in pairs are unaware of other's gender, which is known in treatment $\mathrm{G}$ (awareness of gender constellation); finally, in treatment $\mathrm{E}$ (embeddedness of gender constellation) the field of study of both partners is added to information on gender.

After reading the instructions, participants had to answer a few control questions before the experiment. Actually, we report here only on the choice data of the first phase of a more encompassing experiment with unannounced later rounds allowing for experience and learning effects (Di Cagno et al., mimeo).

\section{Main Findings}

Proceeding as in backward induction, we begin with acceptance decisions $\delta(p, v)$ by seller participants.

Observation 1 One mainly observes $\delta(p, v)=1$ for $p \geq q v$ and $\delta(p, v)=0$ for $p<q v$. There exist no gender (constellation) nor treatment effects in acceptance behavior of seller participants (see Table 1).

Since trade is always efficient due to $(1-q) v>0$, and avoiding a minor loss as a seller might imply a significant gain of $v-p$ for the buyer, these findings question other-regarding concerns: at least for situations when own generosity would let the other gain whereas oneself suffers a (minor) loss, there is no evidence of pro-social behavior according to our data (only $1.8 \%$ in our sample accepted the trade when $p<q v$ ).

"Suspicion" is confounded with the share one wants to gain of the surplus generated by trade. Thus even a buyer who believes in the truth of $\hat{v}$, i.e. expects $\hat{v}(v)=v$, may propose a price $p<\hat{v}$. We do not claim to distinguish pure suspicion and underpricing to guarantee oneself a satisfactory share of the surplus but only maintain that more "suspicion" should increase $\hat{v}-p$.

Observation 2 Male and female buyers do not differ in "suspicion", i.e. we cannot reject that $\hat{v}-p$ is homogeneously distributed for male and female buyer 
Table 1: Seller's acceptance $\delta(p, v)$ by treatment and gender

\begin{tabular}{|c|c|c|c|c|}
\hline \multirow[t]{2}{*}{ Treatments } & \multicolumn{2}{|c|}{ All Treatments } & \multicolumn{2}{|c|}{$\overline{\text { TR E \& G }}$} \\
\hline & $\beta /(\mathrm{se})$ & $\beta /(\mathrm{se})$ & $\beta /(\mathrm{se})$ & $\beta /(\mathrm{se})$ \\
\hline profitability $(p \geq q v)$ & $\begin{array}{c}2.14^{* * *} \\
(0.27)\end{array}$ & $\begin{array}{c}2.15^{* * *} \\
(0.26)\end{array}$ & $\begin{array}{c}2.15^{* * * *} \\
(0.31)\end{array}$ & $\begin{array}{c}2.15^{* * *} \\
(0.31)\end{array}$ \\
\hline Male & $\begin{array}{c}0.23 \\
(0.22)\end{array}$ & & & \\
\hline Partner: Male & & $\begin{array}{l}-0.31 \\
(0.22)\end{array}$ & & \\
\hline TR G & $\begin{array}{l}-0.07 \\
(0.31)\end{array}$ & $\begin{array}{l}-0.07 \\
(0.32)\end{array}$ & & \\
\hline TR E & $\begin{array}{c}0.29 \\
(0.26)\end{array}$ & $\begin{array}{c}0.32 \\
(0.26)\end{array}$ & & \\
\hline $\begin{array}{l}\text { male seller-female buyer } \\
\text { female seller-male buyer } \\
\text { female seller-female buyer }\end{array}$ & & & $\begin{array}{l}-0.22 \\
(0.40) \\
-0.28 \\
(0.41) \\
-0.14 \\
(0.41)\end{array}$ & $\begin{array}{c}-0.08 \\
(0.38) \\
-0.14 \\
(0.38)\end{array}$ \\
\hline male seller-male buyer & & & & $\begin{array}{c}0.14 \\
(0.41)\end{array}$ \\
\hline Constant & $\begin{array}{c}-0.81^{* *} \\
(0.39)\end{array}$ & $\begin{array}{l}-0.59 \\
(0.40)\end{array}$ & $\begin{array}{c}-0.89^{* *} \\
(0.37)\end{array}$ & $\begin{array}{c}-1.03^{* * *} \\
(0.35)\end{array}$ \\
\hline
\end{tabular}

Notes: Probit regressions, Huber -White robust standard errors in parenthesis. In the experimental protocol, $v, q \in(0,100)$.

Significance: $* 0.1, * * 0.05, * * * 0.01$

participants.

Note, however, the significantly lower prices offered to male sellers in Treatment $\mathrm{G}$ (see Table 2). These could be explained by expecting that male sellers overstate more, contrary to our "make-up" hypothesis, or by discrimination of male sellers. Actually, Observation 3 suggests and supports the latter explanation.

We did not expect Observation 2 since evolutionary psychology scholars have observed that females should have evolved more skeptical, e.g. when trying to find a partner to raise offspring (see Buss, 2005). Observation 2 as such does not question this hypothesis since its effect may have been overcompensated by male buyer participants asking for a higher share of surplus for themselves than female participants in this role. This, however, suggests that male participants in the role of a seller also aim at higher shares of the surplus by making up more, i.e. by larger differences $\hat{v}-v$ than those for female seller participants. This can be clearly rejected.

Observation 3 Female sellers participants make up more than male seller participants, i.e. $\hat{v}-v$ is larger for female than for male participants in Treatment $G$ (see Table 3). 
Table 2: Buyer's offered price $p$ by treatment and gender

\begin{tabular}{|c|c|c|c|c|c|c|c|c|}
\hline \multirow[t]{2}{*}{ Treatments } & \multicolumn{2}{|c|}{ TR G } & \multicolumn{2}{|c|}{ TR E } & \multicolumn{2}{|c|}{ TR G } & \multicolumn{2}{|c|}{ TR E } \\
\hline & $\beta /(\mathrm{se})$ & $\beta /(\mathrm{se})$ & $\beta /(\mathrm{se})$ & $\beta /(\mathrm{se})$ & $\beta /(\mathrm{se})$ & $\beta /(\mathrm{se})$ & $\beta /(\mathrm{se})$ & $\beta /(\mathrm{se})$ \\
\hline Male & $\begin{array}{c}6.65 \\
(22.38)\end{array}$ & & $\begin{array}{c}3.89 \\
(9.24)\end{array}$ & & & & & \\
\hline Male $^{*} \hat{v}$ & $\begin{array}{l}-0.06 \\
(0.40)\end{array}$ & & $\begin{array}{l}-0.05 \\
(0.18)\end{array}$ & & & & & \\
\hline Partner:Male & & $\begin{array}{c}-28.97^{*} \\
(15.64)\end{array}$ & & $\begin{array}{c}2.49 \\
(9.54)\end{array}$ & & & & \\
\hline Partner Male* $\hat{v}$ & & $\begin{array}{l}0.49^{*} \\
(0.26)\end{array}$ & & $\begin{array}{l}-0.03 \\
(0.18)\end{array}$ & & & & \\
\hline Female & & & & & $\begin{array}{c}-6.65 \\
(22.38)\end{array}$ & & $\begin{array}{l}-3.89 \\
(9.24)\end{array}$ & \\
\hline Female $^{*} \hat{v}$ & & & & & $\begin{array}{c}0.06 \\
(0.40)\end{array}$ & & $\begin{array}{c}0.05 \\
(0.18)\end{array}$ & \\
\hline Partner:Female & & & & & & $\begin{array}{c}28.97^{*} \\
(15.64)\end{array}$ & & $\begin{array}{c}-2.49 \\
(9.54)\end{array}$ \\
\hline Partner Female* $\hat{v}$ & & & & & & $\begin{array}{c}-0.49^{*} \\
(0.26)\end{array}$ & & $\begin{array}{c}0.03 \\
(0.18)\end{array}$ \\
\hline $\mathrm{q}$ & $\begin{array}{l}0.22^{* *} \\
(0.10)\end{array}$ & $\begin{array}{c}0.21^{* *} \\
(0.09)\end{array}$ & $\begin{array}{c}0.17^{* * * *} \\
(0.06)\end{array}$ & $\begin{array}{c}0.17^{* *} \\
(0.07)\end{array}$ & $\begin{array}{c}0.22^{* *} \\
(0.10)\end{array}$ & $\begin{array}{c}0.21^{* *} \\
(0.09)\end{array}$ & $\begin{array}{c}0.17^{* * *} \\
(0.06)\end{array}$ & $\begin{array}{l}0.17^{* *} \\
(0.07)\end{array}$ \\
\hline$\hat{v}$ & $\begin{array}{c}0.57^{* *} \\
(0.27)\end{array}$ & $\begin{array}{c}0.30 \\
(0.21)\end{array}$ & $\begin{array}{c}0.45^{* * *} \\
(0.11)\end{array}$ & $\begin{array}{c}0.45^{* * *} \\
(0.12)\end{array}$ & $\begin{array}{c}0.51^{*} \\
(0.28)\end{array}$ & $\begin{array}{c}0.79 * * * \\
(0.16)\end{array}$ & $\begin{array}{c}0.41^{* * *} \\
(0.14)\end{array}$ & $\begin{array}{c}0.42^{* * *} \\
(0.13)\end{array}$ \\
\hline Constant & $\begin{array}{c}-8.08 \\
(19.50)\end{array}$ & $\begin{array}{c}11.03 \\
(12.51)\end{array}$ & $\begin{array}{l}-0.35 \\
(6.00)\end{array}$ & $\begin{array}{c}0.28 \\
(4.93)\end{array}$ & $\begin{array}{l}-1.43 \\
(9.66)\end{array}$ & $\begin{array}{c}-17.93^{* *} \\
(8.35)\end{array}$ & $\begin{array}{c}3.54 \\
(7.93)\end{array}$ & $\begin{array}{c}2.77 \\
(8.69)\end{array}$ \\
\hline Observations & 32 & 32 & 96 & 96 & 32 & 32 & 96 & 96 \\
\hline R-squared & 0.411 & 0.474 & 0.344 & 0.342 & 0.411 & 0.474 & 0.344 & 0.342 \\
\hline $\mathrm{F}$ & 8.65 & 16.02 & 9.57 & 12.21 & 8.65 & 16.02 & 9.57 & 12.21 \\
\hline
\end{tabular}

Notes: OLS regressions, Huber -White robust standard errors in parenthesis. In the experimental protocol, $v, q \in(0,100)$.

Significance: $* 0.1,{ }^{* *} 0.05,{ }^{* * *} 0.01$ 
Table 3: Seller's "make-up" $(\hat{v}-v)$ by treatment and gender

\begin{tabular}{l|c|cc||cc|cc}
\hline \hline Treatments & All & \multicolumn{2}{|c}{ TR E \& G } & \multicolumn{2}{c}{ TR G } & \multicolumn{2}{c}{ TR E } \\
\hline & $\beta /(\mathrm{se})$ & $\beta /(\mathrm{se})$ & $\beta /(\mathrm{se})$ & $\beta /(\mathrm{se})$ & $\beta /(\mathrm{se})$ & $\beta /(\mathrm{se})$ & $\beta /(\mathrm{se})$ \\
\hline Male & 1.49 & 1.53 & & -4.25 & & 3.46 & \\
& $(2.70)$ & $(3.42)$ & \multicolumn{1}{|c|}{$(6.85)$} & & $(3.97)$ & \\
Partner: Male & & & -2.50 & & $-17.63^{* * *}$ & & 2.54 \\
& & & $(3.41)$ & & $(6.09)$ & & $(3.97)$ \\
TR G & -1.54 & & & & & & \\
& $(3.99)$ & & & & & & \\
TR E & -2.35 & & & & & & \\
& $(2.90)$ & & & & & & \\
\hline Constant & $5.86^{* *}$ & 3.69 & $5.70^{* *}$ & 7.19 & $13.88^{* * *}$ & 2.52 & 2.98 \\
& $(2.38)$ & $(2.40)$ & $(2.48)$ & $(5.32)$ & $(4.00)$ & $(2.68)$ & $(2.94)$ \\
Observations & 188 & 128 & 128 & 32 & 32 & 96 & 96 \\
R-squared & 0.005 & 0.002 & 0.004 & 0.013 & 0.218 & 0.008 & 0.004 \\
F & 0.31 & 0.20 & 0.54 & 0.39 & 8.37 & 0.76 & 0.41 \\
\hline \hline
\end{tabular}

Notes: OLS regressions, Huber -White robust standard errors in parenthesis. In the experimental protocol, $v, q \in(0,100)$.

Significance: * $0.1, * * 0.05, * * * 0.01$

In our view, Observation 3 justifies the interpretation of Observation 2 as revealing no gender effect in "suspicion", contrary to our expectation based on evolutionary psychology. Taken together, both observations suggest that female participants try to improve their share in bargaining by overstating what they offer, i.e. by making up more.

Observation 4 When female are in both roles there is more "make-up" (see Table 4).

We observe that not only female sellers make up more than male sellers, but they strengthen the "make-up" when matched with the same gender.

\section{Conclusions}

By a modification of the "Acquiring-a-Company" game, we studied in the lab how "make-up", "suspicion" and acceptance depend on gender and gender constellations. We find that female sellers make up more than males, and especially when matched with the same gender. However, we find no gender nor gender constellations or treatment effects on "suspicion" and acceptance. This implies, in particular, that there is no evidence of pro-social behavior, not even in those situations when generosity would let the other to gain at expense of own minor loss. 
Table 4: Seller's "make-up" $(\hat{v}-v)$ by treatment and gender constellation

\begin{tabular}{l|cc||cc|cc}
\hline \hline Treatments & \multicolumn{2}{|c}{ TR E \& G } & \multicolumn{2}{c}{ TR G } & \multicolumn{2}{c}{ TR E } \\
\hline & $\beta /(\mathrm{se})$ & $\beta /(\mathrm{se})$ & $\beta /(\mathrm{se})$ & $\beta /(\mathrm{se})$ & $\beta /(\mathrm{se})$ & $\beta /(\mathrm{se})$ \\
\hline male seller-female buyer & -2.88 & -3.84 & 10.88 & -11.00 & -7.46 & -1.46 \\
& $(4.89)$ & $(4.97)$ & $(8.43)$ & $(7.73)$ & $(5.81)$ & $(5.94)$ \\
female seller-male buyer & -6.91 & $-7.87^{*}$ & -2.50 & $-24.38^{* *}$ & -8.38 & -2.38 \\
& $(4.65)$ & $(4.74)$ & $(9.50)$ & $(8.89)$ & $(5.26)$ & $(5.41)$ \\
female seller-female buyer & 0.97 & & $21.88^{* *}$ & & -6.00 & \\
& $(4.91)$ & & $(7.99)$ & & $(5.71)$ & \\
male seller-male buyer & & -0.97 & & $-21.87^{* *}$ & & 6.00 \\
& & $(4.91)$ & & $(7.99)$ & & $(5.71)$ \\
\hline Constant & $6.66^{*}$ & $7.63^{* *}$ & -2.50 & $19.38^{* * *}$ & $9.71^{* *}$ & 3.71 \\
& $(3.41)$ & $(3.53)$ & $(6.12)$ & $(5.13)$ & $(3.93)$ & $(4.14)$ \\
Observations & 128 & 128 & 32 & 32 & 96 & 96 \\
R-squared & 0.025 & 0.025 & 0.263 & 0.263 & 0.029 & 0.029 \\
F & 1.15 & 1.15 & 3.67 & 3.67 & 0.95 & 0.95 \\
\hline \hline
\end{tabular}

Notes: OLS regressions, Huber -White robust standard errors in parenthesis. In the experimental protocol, $v, q \in(0,100)$.

Significance: $* 0.1, * * 0.05, * * * 0.01$

\section{References}

Buss, D. M. (ed.), 2005. The Handbook of Evolutionary Psycology, Wiley.

Di Cagno, D., Galliera, A., Güth, W., Pace, N., Panaccione, L., 2014. '"Are Women more Suspicious than Men? An Experiment with Prior Value Message before "Acquiring-a-Company"", mimeo

Eckel, C.C., Grossman, P.J., 2001. "Chivalry and Solidarity in Ultimatum Games," Economic Inquiry, vol. 39(2), pages 171-88, April.

García-Gallego, A., Georgantzís, N., Jaramillo-Gutiérrez, A., 2012. "Gender differences in ultimatum games: Despite rather than due to risk attitudes," Journal of Economic Behavior \& Organization, vol. 83(1), pages 42-49.

Gneezy, U., Rustichini, A., 2004. "Gender and Competition at a Young Age," American Economic Review, vol. 94(2), pages 377-381, May.

Mechtenberg, L., 2009. "Cheap Talk in the Classroom: How Biased Grading at School Explains Gender Differences in Achievements, Career Choices and Wages," Review of Economic Studies, vol. 76(4), pages 1431-1459.

Niederle, M., Vesterlund, L., 2007. "Do Women Shy Away from Competition? Do Men Compete Too Much?," The Quarterly Journal of Economics, vol. 122(3), pages 1067-1101, 08. 
Riley, B.H., McGinn, K.L., 2002. "When Does Gender Matter in Negotiation?," Working Paper Series rwp02-036, Harvard University, John F. Kennedy School of Government.

Saad, G., Tripat, G., 2001. "Sex Differences in the Ultimatum Game: An Evolutionary Psychology Perspective," Journal of Bioeconomics, vol. 3(2), pages 171-193, May.

Samuelson, W.F., Bazerman, M. H., 1985. "Negotiation under the winner's curse" Research in Experimental Economics, Vol. III, Smith, V. (ed.).

Solnick, S.J., 2001. "Gender Differences in the Ultimatum Game," Economic Inquiry, vol. 39(2), pages 189-200, April.

Sutter, M., Bosman, R., Kocher M., Winden, F., 2009. "Gender pairing and bargaining-Beware the same sex!," Experimental Economics, vol. 12(3), pages 318-331, September. 